\title{
Blockade of the Sigma-1 Receptor Relieves Cognitive and Emotional Impairments Associated to Chronic Osteoarthritis Pain
}

\section{OPEN ACCESS}

Edited by:

Enrique José Cobos, University of Granada, Spain

Reviewed by:

Filipa Pinto-Ribeiro University of Minho, Portugal Fani Moreira Neto,

Universidade do Porto, Portugal

*Correspondence:

Rafael Maldonado

rafael.maldonado@upf.edu

tThese authors have contributed equally to this work

Specialty section: This article was submitted to Experimental Pharmacology and Drug Discovery

a section of the journal Frontiers in Pharmacology

Received: 22 January 2019 Accepted: 12 April 2019 Published: 03 May 2019

Citation:

Carcolé M, Zamanillo $D$, Merlos M, Fernández-Pastor B, Cabañero D and Maldonado R (2019) Blockade of the Sigma-1 Receptor

Relieves Cognitive and Emotional Impairments Associated to Chronic

Osteoarthritis Pain.

Front. Pharmacol. 10:468. doi: 10.3389/fphar.2019.00468

\begin{abstract}
Mireia Carcolé1, Daniel Zamanillo², Manuel Merlos², Begoña Fernández-Pastor², David Cabañero ${ }^{1+}$ and Rafael Maldonado ${ }^{1 *+}$
\end{abstract}

' Neuropharmacology Laboratory, Department of Experimental and Health Sciences, Pompeu Fabra University, Barcelona, Spain, ${ }^{2}$ Drug Discovery and Preclinical Development, Laboratories Esteve, Barcelona Science Park, Barcelona, Spain

Osteoarthritis is the most common musculoskeletal disease worldwide, often characterized by degradation of the articular cartilage, chronic joint pain and disability. Cognitive dysfunction, anxiety and depression are common comorbidities that impact the quality of life of these patients. In this study, we evaluated the involvement of sigma1 receptor $(\sigma 1 \mathrm{R})$ on the nociceptive, cognitive and emotional alterations associated with chronic osteoarthritis pain. Monosodium iodoacetate (MIA) was injected into the knee of Swiss-albino CD1 mice to induce osteoarthritis pain, which then received a repeated treatment with the $\sigma 1 \mathrm{R}$ antagonist E-52862 or its vehicle. Nociceptive responses and motor performance were assessed with the von Frey and the Catwalk gait tests. Cognitive alterations were evaluated using the novel object recognition task, anxiety-like behavior with the elevated plus maze and the zero-maze tests, whereas depressive-like responses were determined using the forced swimming test. We also studied the local effect of the $\sigma 1 \mathrm{R}$ antagonist on cartilage degradation, and its central effects on microglial reactivity in the medial prefrontal cortex. MIA induced mechanical allodynia and gait abnormalities that were prevented by the chronic treatment with the $\sigma 1 \mathrm{R}$ antagonist. E-52862 also reduced the memory impairment and the depressive-like behavior associated to osteoarthritis pain. Interestingly, the effect of E-52862 on depressive-like behavior was not accompanied by a modification of anxiety-like behavior. The painrelieving effects of the $\sigma 1 R$ antagonist were not due to a local effect on the articular cartilage, since E-52862 treatment did not modify the histological alterations of the knee joints. However, E-52862 induced central effects revealed by a reduction of the cortical microgliosis observed in mice with osteoarthritis pain. These findings show that $\sigma 1 \mathrm{R}$ antagonism inhibits mechanical hypersensitivity, cognitive deficits and depressive-like states associated with osteoarthritis pain in mice. These effects are associated with central modulation of glial activity but are unrelated to changes in cartilage degradation. Therefore, targeting the $\sigma 1 \mathrm{R}$ with E-52862 represents a promising pharmacological approach with effects on multiple aspects of chronic osteoarthritis pain that may go beyond the strict inhibition of nociception.

Keywords: osteoarthritis, pain, sigma-1 receptor, cognition, depression, microglia, medial prefrontal cortex 


\section{INTRODUCTION}

Osteoarthritis is one of the most prevalent chronic diseases and represents a major socio-economic burden worldwide (Johnson and Hunter, 2014; Puig-Junoy and Ruiz Zamora, 2015). It is a complex disease of the whole joint defined by progressive destruction of articular cartilage (Sutton et al., 2009; Zhang et al., 2013). Its most problematic symptoms are pain and loss of joint function, and current pharmacological therapies are limited and generally directed to relief pain. However, osteoarthritis pain is frequently accompanied by co-morbid affective manifestations, such as anxiety and depression (Axford et al., 2010; Goldenberg, 2010; Sharma et al., 2016), and by cognitive alterations including memory dysfunction, which contribute to an overall impairment of the quality of life (Moriarty et al., 2011; Moriarty and Finn, 2014). These co-morbid alterations could in turn aggravate pain perception and contribute to the establishment of chronic osteoarthritis pain (Villemure and Bushnell, 2009). In this context, treatments that simultaneously control the nociceptive, affective and cognitive manifestations could represent an efficient therapeutical approach for chronic osteoarthritis pain.

Sigma-1 receptor $(\sigma 1 \mathrm{R})$ is a ligand-regulated chaperone that interacts with a large number of receptors and ion channels ( $\mathrm{Su}$ and Hayashi, 2003; Hayashi and Su, 2007; Tsai et al., 2009) and has widespread distribution in the nervous system (Harada et al., 1994; Alonso et al., 2000; Kitaichi et al., 2000). Preclinical studies have implicated this receptor in several neurological disorders, such as addiction (Matsumoto et al., 2002; Maurice et al., 2002), schizophrenia (Hayashi et al., 2011) neurodegenerative disorders (Maurice et al., 1998; Francardo et al., 2014) or depression (Urani et al., 2001; Skuza and Rogóz, 2003; Lucas et al., 2008). $\sigma 1 \mathrm{R}$ has also been proposed as an effective therapeutic target in several models of chronic pain (Entrena et al., 2009; Nieto et al., 2012; Romero et al., 2012; Gris et al., 2014; Tejada et al., 2014). However, these studies do not assess the participation of the $\sigma 1 \mathrm{R}$ on the emotional or cognitive alterations that can develop after the induction of persistent pain (La Porta et al., 2015, 2016; Negrete et al., 2017). Thus, it remains to be determined whether $\sigma 1 \mathrm{R}$ ligands could be effective relieving chronic osteoarthritis pain together with its co-morbid cognitive and affective impairments.

The prefrontal cortex plays a crucial role in emotional processing (Gusnard et al., 2001; Etkin et al., 2011), cognitive functions (Phelps et al., 2004) and modulation of pain perception (Apkarian et al., 2004, 2005; Metz et al., 2009). Clinical studies have observed functional and structural abnormalities in the prefrontal cortex of patients suffering from chronic pain (Apkarian et al., 2004; Seminowicz et al., 2011). Such anatomical alterations have also been observed in animal models of neuropathic pain, where a decreased volume of the prefrontal cortex was found in correlation with anxiety-like behavior (Seminowicz et al., 2009). Several studies have also revealed the important role of microglial cells in the adaptative changes occurring in the central nervous system during chronic pain, leading to the persistence of pain manifestations (Racz et al., 2008). The role of microglia on chronic pain has been revealed in the spinal cord (Racz et al., 2008), and supraspinal activation of microglia is also partly responsible for the structural, functional, and molecular neuroplasticity associated with pathological pain (Boadas-Vaello et al., 2017). In fact, it has been proposed that microglial alterations in cortical regions underlie pain-induced emotional and cognitive impairments (Panigada and Gosselin, 2011). Therefore, targeting microglial reactivity in these areas could be an appropriate strategy to treat the affective and memory disturbances observed in chronic pain conditions. Interestingly, $\sigma 1 \mathrm{R}$ is highly expressed in microglia (Gekker et al., 2006) where it exerts a modulatory function (Peviani et al., 2014; Moritz et al., 2015). Therefore, it would be important to elucidate the possible role of $\sigma 1 \mathrm{R}$ on cortical microgliosis associated to chronic osteoarthritis pain.

Here we assessed the effect of the $\sigma 1 \mathrm{R}$ antagonist E-52862, also named S1RA (Romero et al., 2012; Gris et al., 2014) and MR309 (Castany et al., 2018), on the nociceptive, cognitive and emotional alterations observed in the monosodium iodoacetate (MIA) model of osteoarthritis pain in mice. To determine whether E-52862 exerts its effects through a local participation of $\sigma 1 \mathrm{R}$ on the knee joint, we analyzed levels of cartilage degradation through histological assessment. In addition, we evaluated possible central neuroplastic effects of the $\sigma 1 \mathrm{R}$ antagonist by determining microglial density and morphology in the medial prefrontal cortex.

\section{MATERIALS AND METHODS}

\section{Animals}

Swiss albino male mice (Charles River, Lyon, France) 8-12 weeks old were used in all the experiments. Mice weighted 22-24 g at the beginning of the experiments and were housed in groups of 3-4 with free access to water and food. The housing conditions were maintained at $21 \pm 1^{\circ} \mathrm{C}$ and $55 \pm 10 \%$ relative humidity in a controlled light/dark cycle (light on between 8:00 a.m. and 8:00 p.m.). During the weekly home cage replacement, the nest and an ounce of the old bedding were kept to reduce stress, and it was scheduled for days without any behavioral testing to avoid interferences. Six to 8 animals were used for each experimental group for behavioral testing, and 5-7 animals for the histological scoring, using a total of 53 mice. All experimental procedures and animal husbandry were conducted following the ARRIVE (Animal Research: Reporting In Vivo Experiments) guidelines and according to the ethical principles of the International Association for the Study of Pain (I.A.S.P.) for the evaluation of pain in conscious animals (Zimmermann, 1986) and the European Parliament and the Council Directive (2010/63/EU), and were approved by the Animal Care and Use Committees of the PRBB and Departament de Territori $i$ Habitatge of Generalitat de Catalunya. All the experiments were performed under blinded conditions.

\section{Intra-Articular Injection of MIA}

Osteoarthritis pain was induced in mice briefly anesthetized with isoflurane $(2 \% \mathrm{v} / \mathrm{v})$ vaporized in oxygen. The joint was shaved and flexed at a $90^{\circ}$ angle and $10 \mu \mathrm{l}$ of MIA (10 mg/mL, Sigma, United Kingdom) dissolved in sterile saline $(\mathrm{NaCl} 0.9 \%)$ were 
intra-articularly injected with a 30 -gauge needle. Control mice received the same volume of sterile saline.

\section{Nociceptive Behavior}

Hypersensitivity to punctate stimuli (von Frey filaments), which will be referred as mechanical allodynia throughout the text, was used as outcome measure of osteoarthritis pain. For this purpose, hind paw withdrawal response to von Frey filament stimulation was assessed (Chaplan et al., 1994). Briefly, animals were placed in Plexiglas cylinders $(20 \mathrm{~cm}$ high, $9 \mathrm{~cm}$ diameter) positioned on a grid surface through which calibrated von Frey filaments (North Coast Medical, United States) were applied following the up-down paradigm, as previously reported (Chaplan et al., 1994). The 0.4-g filament was used first, and the strength of the next filament was decreased or increased according to the response following this sequence $0.07,0.16,0.4,0.6,1.0$, 2.0. The 2.0-g filament was used as a cut-off. The mechanical threshold (in grams) was then calculated with the up-down Excel program (Dixon, 1965). Animals were habituated for 3 consecutive days ( $2 \mathrm{~h}$ per day) to the von Frey environment before the baseline measurements and for $1 \mathrm{~h}$ before testing to allow appropriate behavioral immobility. Clear paw withdrawal, shaking or licking was considered as nociceptive response. Both ipsilateral and contralateral hind paws were tested. Only ipsilateral responses are shown, since contralateral sides showed no significant differences.

\section{Gait Analysis}

We used the Catwalk automated gait analysis (Noldus, Netherlands) to assess the effects of osteoarthritis pain on gait (Vrinten and Hamers, 2003; Ferland et al., 2011). Each mouse was placed individually in the Catwalk walkway, which consists of a glass plate $(100 \mathrm{~cm} \times 15 \mathrm{~cm} \times 0.6 \mathrm{~cm})$ plus two Plexiglas walls, spaced $5 \mathrm{~cm}$ apart. Mice were allowed to walk freely and traverse from one side to the other of the walkway glass plate. The recordings were carried out when the room was completely dark. A pair of infrared beams spaced $90 \mathrm{~cm}$ apart were used to detect mouse arrival and to control (start/stop) data acquisition. LED light from an enhanced fluorescent lamp was emitted inside the glass plate and completely internally reflected. Where mice paws made contact with the glass plate, light was reflected down, and the illuminated contact areas were recorded with a high-speed color video camera. The camera was positioned underneath the glass plate connected to a computer that run the Catwalk software 9.1. The software regarded a run as compliant if the animal did not show a maximum speed variation greater than $40 \%$. Three compliant runs (trial) were recorded for each animal and time point. The software automatically labeled all the areas containing pixels above the set thresholds. These areas were identified and assigned to the respective paws. Data were segmented to only take into account sequences with a minimum number of 10 consecutive steps per run and an average speed between 20 and $90 \mathrm{~cm} / \mathrm{s}$. Print area (complete surface area contacted by the paw during a stance phase), maximal contact area (maximum area of a paw that comes into contact with the glass plate), swing (duration in sec of no contact of a paw with the glass plate) and duty cycle (duration in sec of contact of a paw with the glass plate as percentage of a whole step cycle) were analyzed. A ratio between right and left hind paws was calculated.

\section{Cognitive Behavior}

Object recognition memory was assessed with the V-maze (Panlab, Barcelona, Spain) to measure cognitive performance, as previously described (Puighermanal et al., 2009; Saravia et al., 2019). V-maze consisted on an apparatus made of black plexiglass with two corridors ( $30 \mathrm{~cm}$ long $\times 4.5 \mathrm{~cm}$ wide) set in $\mathrm{V}$ with a $90^{\circ}$ angle and $15 \mathrm{~cm}$-high walls. This task consists of 3 sessions of 9 min each (habituation, training and test). On day 1 , mice were ${ }^{1}$ habituated to the empty maze. On the 2 nd day, mice were put back and 2 identical objects were presented at the end of each of the corridors. Mice were placed again in the maze $24 \mathrm{~h}$ later and one of the familiar objects was replaced with a novel object. Time exploring each of the 2 objects (novel and familiar) was recorded. A discrimination index [(time exploring the novel object - time exploring the familiar)/(time exploring novel + familiar $) * 100]$ was used as outcome measure of cognitive behavior. High values of discrimination represent good recognition memory. Total time of exploration of the 2 objects was used as a measure of locomotor activity.

\section{Affective Behavior}

The elevated plus maze was used to evaluate anxiety 11 days after saline or MIA injection. It was performed in a black Plexiglas apparatus with 4 arms ( $29 \mathrm{~cm}$ long $\times 5 \mathrm{~cm}$ wide), 2 open and 2 closed, set in cross from a neutral square $(5 \mathrm{~cm} \times 5 \mathrm{~cm})$ elevated $30 \mathrm{~cm}$ above the floor and indirectly illuminated from the top (40-50 lux in the open arms/4-6 lux in the close arms). 5-min test sessions were performed, and the latency to the first entrance to the open arms and the percentage of entries and time spent in the open arms were used as a measure of anxiety-like behavior (Cruz et al., 1994). Mice were habituated to the testing room for $1 \mathrm{~h}$ before starting the evaluation, and the equipment was carefully cleaned between subjects.

The elevated zero maze was used as additional measure of anxiety-like behavior 21 days after saline or MIA injection. Mice were placed in a black Plexiglas apparatus with a round shape, where 2 quarters of the maze were closed by walls $(20 \mathrm{~cm}$-high) and elevated $30 \mathrm{~cm}$ above the floor. Sessions were $5 \mathrm{~min}$ long, and the latency to the open quadrants and the percentage of time spent in the open parts was determined (Shepherd et al., 1994). Mice were habituated to the testing room for $1 \mathrm{~h}$ before starting the evaluation, and the equipment was carefully cleaned between subjects.

The forced swimming test was used to evaluate depressive-like behavior 25 days after saline/MIA (Porsolt et al., 1977). Mice were placed for $6 \mathrm{~min}$ into transparent Plexiglass cylinders $(17.5 \mathrm{~cm}$ high and $12.5 \mathrm{~cm}$ diameter) filled with $15 \mathrm{~cm}$ of water at $22 \pm 2^{\circ} \mathrm{C}$. The percentage of time of immobility was assessed for the last 4 min. Immobility was considered when the animal made no movements in order to escape (swimming, climbing the walls).

\footnotetext{
${ }^{1}$ https://www.ebi.ac.uk/gxa/genes/ENSG00000147955?bs=\%7B\%22homo\% 20sapiens\%22\%3A\%5B\%22ORGANISM_PART\%22\%5D\%7D\&ds=\%7B \% 22kingdom\%22\%3A\%5B\%22animals\%22\%5D\%7D\#baseline
} 
Mice were habituated to the testing room for $1 \mathrm{~h}$ before starting the evaluation, the equipment was carefully cleaned, and the water was changed between subjects.

\section{Experimental Protocol}

Animals were carefully handled and habituated to the von Frey environment for 3 consecutive days before the baseline measurement. The day following baseline nociceptive assessment, MIA or saline was injected into the knee joint. Mice were intraperitoneally treated twice a day (10 a.m. and 06 p.m.) with either vehicle or E-52862 $(20 \mathrm{mg} / \mathrm{kg})$ from the 1 st day after the intra-knee injection to the end of the experiment on day 25. Mechanical sensitivity was evaluated 5 and 19 days after the intra-articular injection with the von Frey test, and at days 6 and 12 with the Catwalk gait test. Nociceptive assessments were performed $30 \mathrm{~min}$ after drug administration. Cognitive and affective behavior were also analyzed. For this purpose, the elevated plus maze was performed 11 days after intra-knee injection, the novel object recognition task at days 13,14, and 15 (habituation, training, and test), the zero-maze at day 21 and the forced swimming test at day 25 after MIA/saline. The late anxiety-like behavior was assessed with a different test from the early evaluation to avoid the well-reported one-trial tolerance to the behavioral test (File et al., 1990; Holmes and Rodgers, 1998). The days of the evaluation of affective behavior, E-52862-treated mice received vehicle instead of the $\sigma 1 \mathrm{R}$ antagonist $30 \mathrm{~min}$ before the test to avoid acute effects of the drug, and E-52862 was administered after the test to continue the repeated treatment. An additional group of vehicle-treated mice received a single dose of E-52862 before the novel object recognition task. Tissue for immunofluorescence analysis was extracted on day 26 and $12 \pm 1 \mathrm{~h}$ after the last drug administration.

\section{Drugs}

The selective $\sigma 1 \mathrm{R}$ antagonist E-52862 [(4-[5-methyl-1(2-naphthalenyl)-1H-pyrazol-3-yl]oxy]ethyl] morpholine hydrochloride] was developed and supplied by Laboratories Esteve (Barcelona, Spain). E-52862 was dissolved in an aqueous solution ( $0.5 \%$ hydroxypropylmethyl cellulose, HPMC; SigmaAldrich) and administered by intraperitoneal route at a volume of $10 \mathrm{ml} / \mathrm{kg} 30 \mathrm{~min}$ before behavioral testing.

\section{Histology}

\section{Knee Joint Isolation}

A separate group of mice was intra-knee injected with saline or MIA and intraperitoneally repeatedly treated with vehicle or E-52862. Mice were sacrificed by cervical dislocation 29 days after the experimental induction of osteoarthritis pain. The ipsilateral knee joints were subsequently removed, post-fixed $48 \mathrm{~h}$ in $4 \%$ paraformaldehyde, and then cryopreserved in $30 \%$ sucrose solution at $4^{\circ} \mathrm{C}$.

\section{Histological Preparation}

The fixed knee joints were decalcified in Osteomoll (Merck, Germany) for 6-7 h and left overnight in 30\% sucrose solution. The joints were subsequently embedded in gelatine $(7.5 \%)$ and frozen in cold 2-methyl-butane. Coronal 16- to 18 - $\mu \mathrm{m}$ sections were cut in a cryostat from the frontal plane toward the back of each joint and mounted on gelatinized slides (6-7 slides with 10 sections each). All the serial sections were stained with the Safranin O-Fast Green staining protocol. Briefly, after hydrating sections with decreasing concentrations of ethanol, sections were stained with haematoxylin (Merck, Germany) and subsequently with $0.002 \%$ Fast Green (Sigma, Spain) and $0.2 \%$ Safranin O (Merck, Germany) solutions. The sections were finally dehydrated and cleared with increasing ethanol concentrations and xylene, then mounted with Eukitt (O. Kindler, Germany) and a covering glass. All the stained sections were viewed with a $10 \times$ objective using a Leica DMR microscope equipped with a Leica DFC 300 FX digital camera. Nine images of the obtained sections spanning the central load-bearing region of the knee were taken for both medial and lateral sides of each joint (18 total images per joint) and used for histological scoring.

\section{Histological Scoring}

A semiquantitative scoring system for murine histopathology, the OARSI score (Glasson et al., 2010) was applied and adapted to our experimental conditions (Figure 2C). All 4 quadrants of the knee joint were evaluated: medial femoral condyle (MFC), lateral femoral condyle (LFC), medial tibial plateau (MTP), and lateral tibial plateau (LTP). A score from 0 to 6 was given to each quadrant of 9 serial sections per animal, having a total of 36 values per animal. The final histological scores were expressed as the sum of all the individual values and the average summed score for each experimental group was calculated. The same observer scored all the histological changes and was blinded to the specimen samples.

\section{Tissue Isolation}

On day 26 after osteoarthritis induction, both MIA and saline mice were deeply anesthetized by intraperitoneally injection $(0.2 \mathrm{ml} / 10 \mathrm{~g}$ of body weight $)$ of a mixture of ketamine $(100 \mathrm{mg} / \mathrm{kg})$ and xylazine $(20 \mathrm{mg} / \mathrm{kg})$ prior to intracardiac perfusion of $4 \% \mathrm{PFA}$ in $0.1 \mathrm{M} \mathrm{Na} 2 \mathrm{HPO}_{4} / \mathrm{NaH}_{2} \mathrm{PO}_{4}$ buffer, $\mathrm{pH}$ 7.5, delivered with a peristaltic pump at $22 \mathrm{ml}$ per $\min$ for $2 \mathrm{~min}$. Brains were removed and post-fixed overnight at $4^{\circ} \mathrm{C}$ in the same fixative solution. Then, brains were transferred to a solution of $30 \%$ sucrose in $\mathrm{PB}$ $0.1 \mathrm{M}$ and kept at $4^{\circ} \mathrm{C}$. Coronal brain sections $(30 \mu \mathrm{m})$ containing the prelimbic and infralimbic prefrontal cortex were obtained with a microtome (Leica) and kept in a solution of $5 \%$ sucrose $\mathrm{PB} 0.1 \mathrm{M}$ at $4^{\circ} \mathrm{C}$ until processed for immunofluorescence analysis.

\section{Immunofluorescence}

Free-floating slices were rinsed in $\mathrm{PB} 0.1 \mathrm{M}$ and blocked in a solution containing $3 \%$ normal goat serum and $0.3 \%$ Triton $\mathrm{X}-100$ in $\mathrm{PB} 0.1 \mathrm{M}$ during $2 \mathrm{~h}$ at room temperature. The slices were incubated overnight at $4^{\circ} \mathrm{C}$ with the primary antibody anti-Iba-1 (1:500, rabbit, Wako). The next day, after 3 rinses in $\mathrm{PB} 0.1 \mathrm{M}$, sections were incubated for $2 \mathrm{~h}$ at room temperature with the secondary antibody AlexaFluor-555 goat anti-rabbit (1:1000, Life Technologies). Then, slices were 
rinsed 3 times and mounted with Fluoromount onto glass slides coated with gelatine.

\section{Immunofluorescence Image Analysis}

The stained sections were analyzed with the $40 \times$ objective and $1 \times$ zoom using a confocal microscope (Leica TCS SP5 STED). A $z$-stack image of $30 \mu \mathrm{m}$ with 0.5 depth intervals was obtained from every slice. Density ${ }^{2}$ and cell architecture of microglia was examined using the ImageJ analysis software. The perimeter of microglial soma was measured using the tool "Freehand line" and the option "Analyze and Measure." Four images per brain area of 6 animals per group were analyzed.

\section{Statistical Analysis}

A 3-way repeated measure analysis of variance (ANOVA) with surgery and treatment as between-subject factors and day as within-subject factor was used to analyze von Frey and gait data. 2-way ANOVA (surgery and treatment) was used to analyze affective behavioral data, as well as the histological scoring from the joint, and 1-way ANOVA was used to analyze the cognitive behavior. In all comparisons, Fisher Least Significant Difference (LSD) post hoc analysis was applied when appropriate (significant interaction between factors). STATISTICA 6.0 (StatSoft, Inc., Tulsa, OK, United States) software was used. The differences were considered statistically significant when the $P$-value was below 0.05 (Supplementary Table S1).

\section{RESULTS}

\section{The o1R Antagonist E-52862 Reverses Mechanical Hypersensitivity Associated to Osteoarthritis Pain}

To evaluate the effect of E-52862 on mechanical hypersensitivity associated to osteoarthritis pain, mice were intraperitoneally treated twice a day with either vehicle or E-52862 $(20 \mathrm{mg} / \mathrm{kg})$ from the 1st day after MIA injection until the end of the experiment (day 25). Von Frey test was performed before and 5 and 19 days after MIA injection, and gait analysis was evaluated at 6 and 12 days (Figure 1A). MIA injection induced a persistent mechanical hypersensitivity in vehicle-treated mice $(p<0.001$ vs. saline mice, days 5 and 19). Conversely, this decrease in mechanical thresholds was absent in mice treated with E-52862 $(p<0.001$ vs. MIA vehicle mice, days 5 and 19) (Figure 1B). Gait analysis also showed MIA-induced alterations on walking patterns that were partly reversed by E-52862. Mice injected with MIA and treated with vehicle showed a significant decrease of the print area $(p<0.01$ vs. saline; Figure 1C) and maximal contact area ( $p<0.05$ vs. saline; Figure 1D) at both time points tested. These alterations were not observed when MIA-injected mice were treated with E-52862 (Figures 1C,D). No significant effects were observed in the swing for any of the experimental groups (Figure 1E), however, a trend toward a decreased duty

${ }^{2}$ https://www.proteinatlas.org/ENSG00000147955-SIGMAR1/tissue cycle was observed in MIA mice treated with vehicle ( $p=0.08$ vs. saline; Figure 1F). Therefore, blocking the $\sigma 1 \mathrm{R}$ produced a relief of mechanical pain associated to the injection of MIA that was also reflected into a normalization of gait function.

\section{MIA Injection Into the Knee Produces Cartilage Degradation Insensitive to the o1R Antagonist E-52862}

Monosodium iodoacetate is a chondrocyte glycolytic inhibitor which produces chondrocyte death and damage in the entire joint space. We determined the level of cartilage degeneration through proteoglycan staining 29 days after the intra-knee injection (Figure 2A). MIA injected mice had a clear increase on the OARSI score when compared to saline mice $(p<0.001$; Figure 2B), and no significant effect of the E-52862 treatment (20 $\mathrm{mg} / \mathrm{kg}$, twice daily during 25 days) was found. Therefore, joint damage was not significantly prevented by the blockade of $\sigma 1 \mathrm{R}$.

\section{Acute and Chronic Blockade of $\sigma 1 R$ Avoid Osteoarthritis-Induced Cognitive Impairment}

Chronic pain is often accompanied by memory dysfunction. Therefore, we analyzed the effect of chronic treatment with E$52862(20 \mathrm{mg} / \mathrm{kg}$, twice daily during 25 days $)$ over recognition memory in the osteoarthritis model (Figure 3A). The novel object recognition task performed 15 days after MIA/saline injection showed a significant decrease on the discrimination index of MIA-injected mice treated with vehicle ( $p<0.001$ vs. saline). This cognitive impairment was avoided after the chronic treatment with E-52862 ( $p<0.05$ vs. MIA vehicle; Figure 3B). Interestingly, MIA-injected mice receiving a single acute dose of the $\sigma 1 \mathrm{R}$ antagonist $(20 \mathrm{mg} / \mathrm{kg}) 30 \mathrm{~min}$ before the test also showed an improvement on the discrimination index $(p<0.001$ vs. MIA vehicle) (Figure 3B). All groups of mice showed similar total exploration times, suggesting normal locomotor activity in this paradigm regardless of the surgery or the treatments (Figure 3C). Therefore, the impairment of recognition memory caused by chronic osteoarthritis pain was improved after chronic or acute blockade of $\sigma 1 \mathrm{R}$.

\section{E-52862 Decreases Depressive-Like Behaviour Associated to Osteoarthritis Pain}

Anxiety and depressive-like behavior were assessed to determine whether E-52862 $(20 \mathrm{mg} / \mathrm{kg}$, twice daily during 25 days $)$ could modulate emotional-like states associated to osteoarthritis pain (Figure 4A). It has been proposed that the initial stages of osteoarthritis pain are associated with inflammatory processes, whereas later stages involve neuropathic components, which may differentially affect the emotional manifestations. Thus, early and late anxiety-like behavior was assessed in our model. Early anxiety was evaluated 11 days after intra-knee injection in the elevated plus maze. No differences were found between saline- and MIAinjected mice in the latency to entry to the open arms, and the percentage of time and entries to the open arms, regardless 


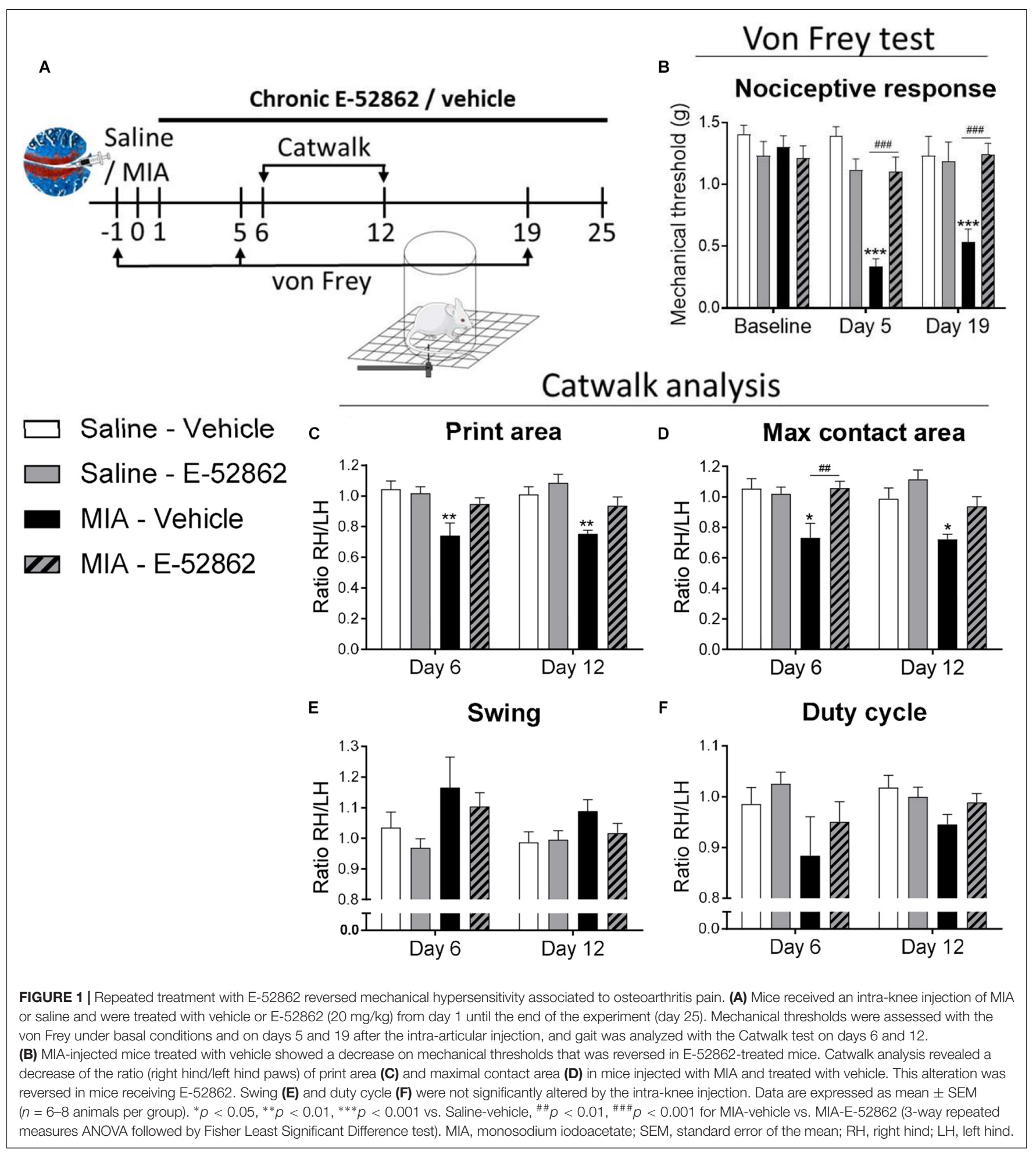

of the treatment received (Figures 4B-D). On the other hand, despite the latency to the open quadrants of the zero-maze was not altered (Figure 4E), mice with osteoarthritis pain showed late anxiety-like behavior reflected in a significant decrease of the time spent in the open arms of the zero-maze $(p<0.001$ vs. saline), also regardless of the treatment. Thus, E-52862 did not normalize the anxiogenic-like responses induced by MIA (Figure 4F). Depressive-like behavior was analyzed in the forced swimming test 25 days after the intra-articular injection. In this paradigm, mice with osteoarthritis pain receiving vehicle showed a significant increase on immobility time ( $p<0.05$ vs. saline; Figure 4G). Chronic E-52862 administration prevented such an 


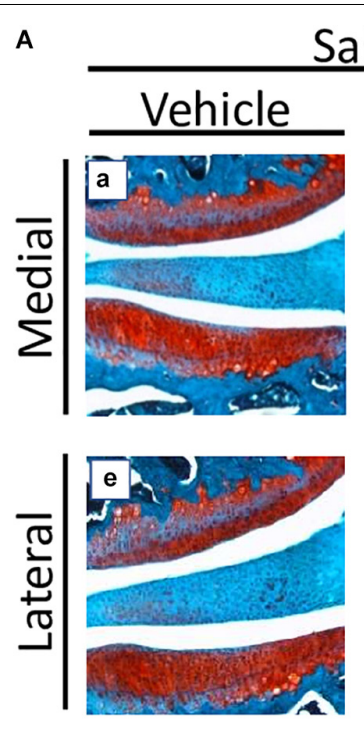

B

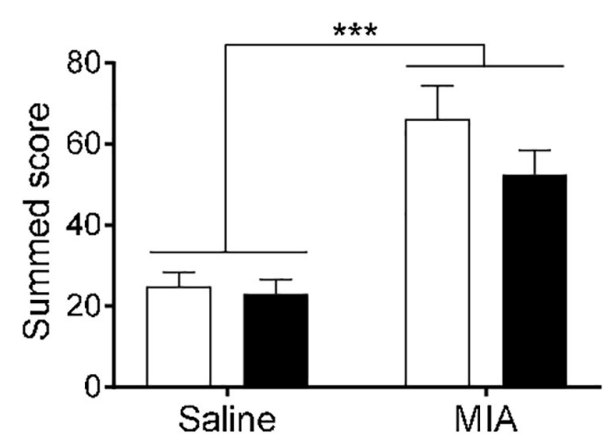

$\square$ Vehicle
E-52862 aline
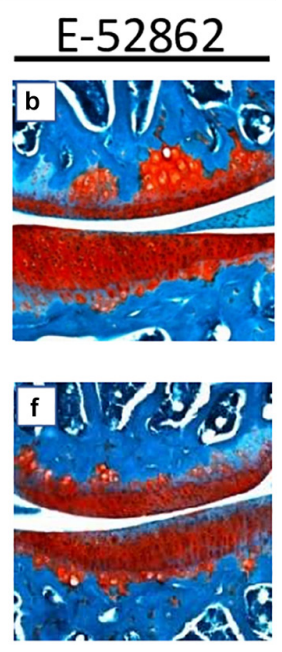

C

(a)
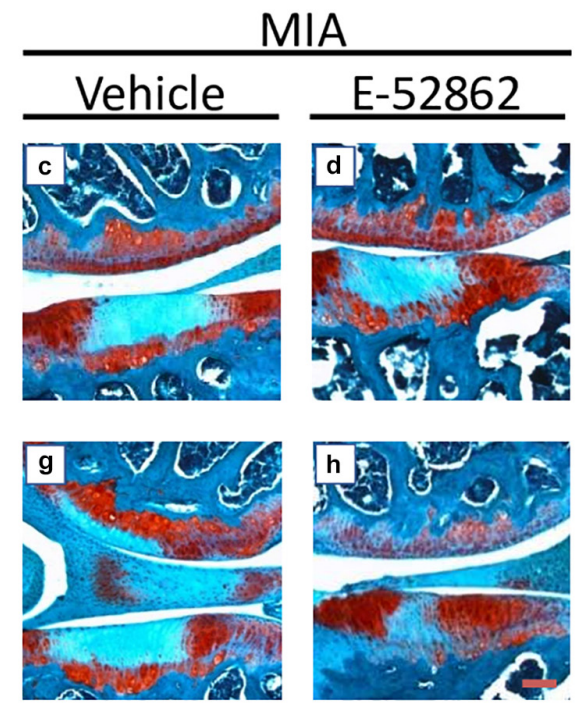

Grade Osteoarthritic damage

Normal

0.5 Small fibrillations at the edge of the cartilage

1 Loss of Safranin-O or small vertical clefts in the superficial layer

2 Loss of Safranin-O in deeper layers

3 Loss of Safranin-O $<25 \%$ of the articular surface) with complete lack of cell nuclei

4 Loss of Safranin-O (25 - 50\% of the articular surface) with complete lack of cell nuclei

5 Loss of Safranin-O ( $50-75 \%$ of the articular surface) with complete lack of cell nuclei

6 Loss of Safranin-O ( $>75 \%$ of the articular surface) with complete lack of cell nuclei

FIGURE 2 | Histological knee alterations in mice injected with MIA were not prevented by the chronic treatment with E-52862. Ipsilateral knees of saline and MIA mice were obtained 29 days after intra-articular injection in mice receiving vehicle or E-52862 treatment. (A) Medial and lateral sides of the joints are represented, showing the femur condyle (above) and the tibial plateau (below). (B) The injection of MIA produced cartilage degeneration revealed by an increased OARSI score. Treatment with E-52862 (20 mg/kg, twice daily during 25 days) did not prevent the joint damage. (C) The semiquantitative scoring system for joint histopathology. The scores for each image are (first value represents femur condyle and second value represents tibial plateau): (a) 1, 0.5; (b) 0.5, 0; (c) 2, 5; (d) 2, 5; (e) 2, 0.5; (f) 0, 0.5; (g) 3, 6; (h) 2, 3. Data are expressed as the mean \pm SEM ( $n=5-7$ animals per group). Scale bar: $100 \mu \mathrm{m}$. ${ }^{* * *} p<0.001$ for saline vs. MIA (2-way ANOVA). MIA, monosodium iodoacetate; SEM, standard error of the mean.

increase in despair-like behavior $(p<0.01$ vs. MIA vehicle; Figure 4G). Therefore, anxiety-like behavior was not sensitive to $\sigma 1 \mathrm{R}$ antagonism, whereas MIA-induced depressive-like behavior was prevented after E-52862 treatment.

\section{E-52862 Modulates Microglial Expression in the Medial Prefrontal Cortex}

A possible central role of $\sigma 1 \mathrm{R}$ modulating microglial activity was assessed through quantification of the density of microglial cells and the perimeter of the somas in the prelimbic and infralimbic areas of the medial prefrontal cortex (Figure 5). The analysis of the cellular density showed a significant increase on the total number of microglial cells in the prelimbic and the infralimbic areas of mice with osteoarthritis pain receiving vehicle ( $p<0.001$ vs. saline) (Figures 5A,C,D,F). Repeated administration of the $\sigma 1 \mathrm{R}$ antagonist $(20 \mathrm{mg} / \mathrm{kg}$, twice daily during 25 days) significantly reduced the microglial density in both cortical areas $(p<0.01$ vs. MIA vehicle; Figures 5A,C,D,F). MIA-injected mice had an increase of the perimeter of microglial cells in the infralimbic $(p<0.05$; 


\section{A}

Chronic E-52862 / vehicle

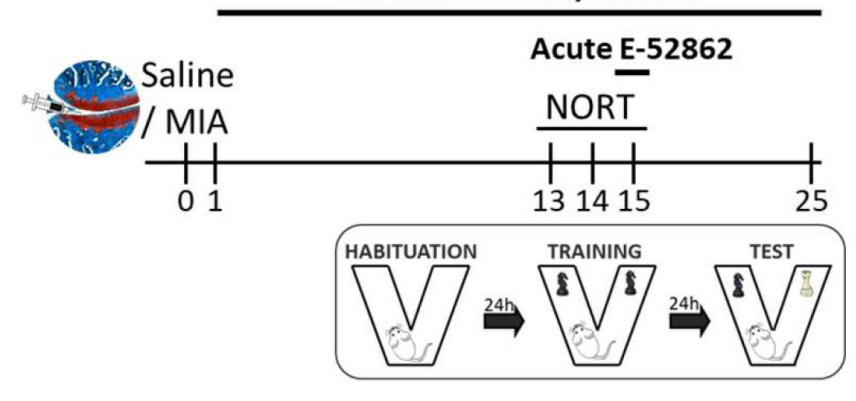

B

Discrimination index

c Total exploration time
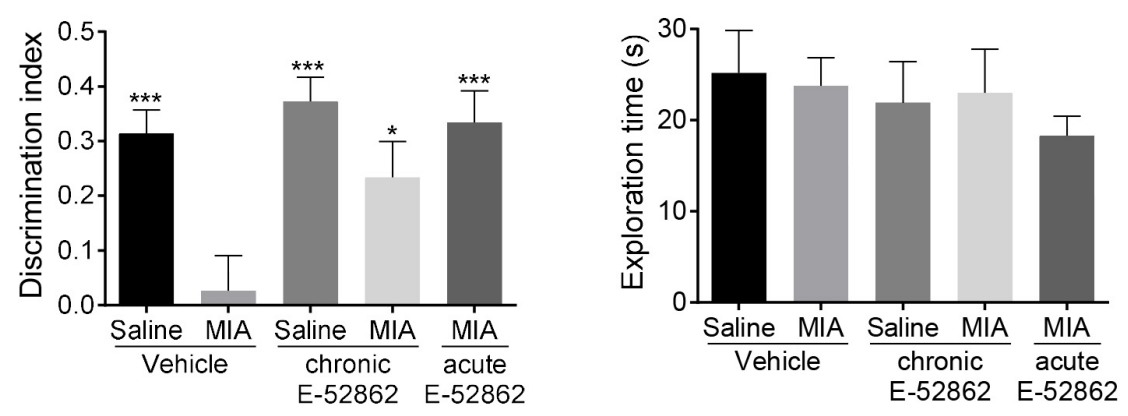

FIGURE 3 | Acute and chronic treatments with E-52862 improved the cognitive deficits induced by MIA injection. (A) Saline or MIA-injected mice treated with vehicle or E-52862 (20 mg/kg, twice daily during 25 days) were evaluated for recognition memory 15 days after the intra-knee injection in the novel object recognition test (NORT). (B) Mice with osteoarthritis pain treated with vehicle showed decreased discrimination index indicating a memory impairment. Acute and chronic treatment with E-52862 reversed the cognitive deficits induced by MIA. (C) Animals revealed similar total exploration times regardless of the surgery or the treatment. Data are expressed as mean \pm SEM ( $n=6-8$ animals per group). ${ }^{*} p<0.05,{ }^{* * *} p<0.001 \mathrm{vs.} \mathrm{MIA-vehicle} \mathrm{(1-way} \mathrm{ANOVA} \mathrm{followed} \mathrm{by} \mathrm{Fisher} \mathrm{least} \mathrm{significant} \mathrm{difference} \mathrm{test).}$ MIA, monosodium iodoacetate; SEM, standard error of the mean.

Figure 5E), but not in the prelimbic area (Figure 5B) when compared to saline-injected mice. This increase was not significantly affected by the treatment with E-52862. Therefore, E-52862 modulated the density of microglial cells in the medial prefrontal cortices without affecting microglia activation.

\section{DISCUSSION}

The present study reveals the involvement of the $\sigma 1 \mathrm{R}$ in the nociceptive, emotional and cognitive alterations associated with osteoarthritis pain in mice. Mechanical allodynia and gait impairments induced by MIA injection were partly prevented by chronic administration of the $\sigma 1 \mathrm{R}$ antagonist E-52862. This treatment also inhibited the cognitive deficits and depressive-like behavior of mice with osteoarthritis pain, although anxiogeniclike responses were not modified. Modulation of the paininduced behavioral alterations by E-52862 was not due to an inhibition of joint damage produced by MIA, and there was a concomitant decrease on MIA-induced microgliosis in the medial prefrontal cortex.

$\sigma 1 \mathrm{R}$ is highly expressed in key areas for pain control (Alonso et al., 2000; Bangaru et al., 2013). Behavioral studies have shown analgesic efficacy of the $\sigma 1 \mathrm{R}$ antagonist E-52862 in acute (Romero et al., 2012; Gris et al., 2014; Tejada et al.,
2014) and chronic (Gris et al., 2014) models of inflammatory pain, and in neuropathic pain models induced by partial sciatic nerve ligation (Romero et al., 2012), chemotherapy (Nieto et al., 2012), or streptozotocin-induced diabetes (Gris et al., 2016). However, the role of $\sigma 1 \mathrm{R}$ has not been previously assessed in models of osteoarthritis pain, one of the most prevalent and disabling chronic pain conditions. We showed that E-52862 inhibited both mechanical hypersensitivity and gait alterations in the MIA model of osteoarthritis pain. Gait alterations could be associated to structural modifications of the joint or to the increased mechanical sensitivity (Boettger et al., 2009). Previous studies using the antigen-induced arthritis model in rats suggested that specific gait parameters, such as the angle between the paws, were exclusively influenced by the structural damage of the joint as indicated by its correlation with cartilage destruction (Boettger et al., 2009). However, other parameters, such as the paw print area, represent good measures of pain (Boettger et al., 2009). The correlation with mechanical allodynia would be in agreement with previous work showing that nerve-injured rats with decreased mechanical thresholds to punctate stimulation had also altered walking patterns (Vrinten and Hamers, 2003). In the same line, the MIA model of osteoarthritis pain in rodents showed that celecoxib and morphine reduced mechanical allodynia and gait abnormalities (Ferland et al., 2011; Ferreira-Gomes et al., 2012), suggesting that both parameters are associated in this 
A Chronic E-52862 / vehicle

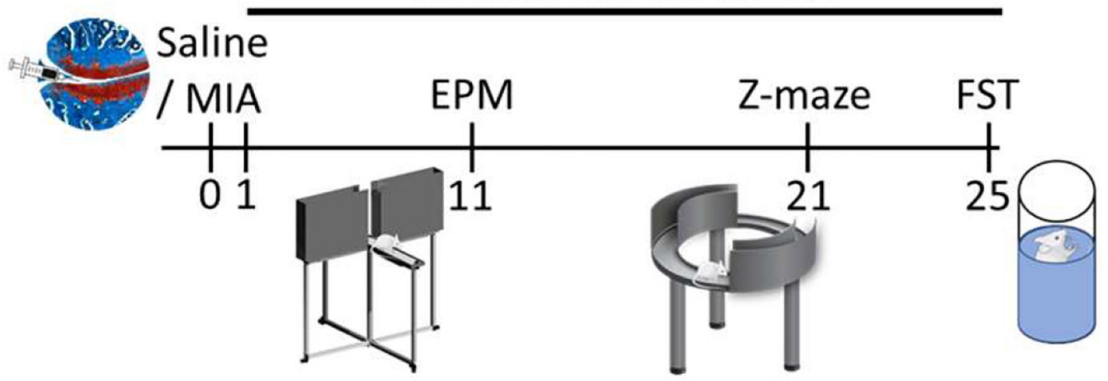

Early anxiety-like behaviour
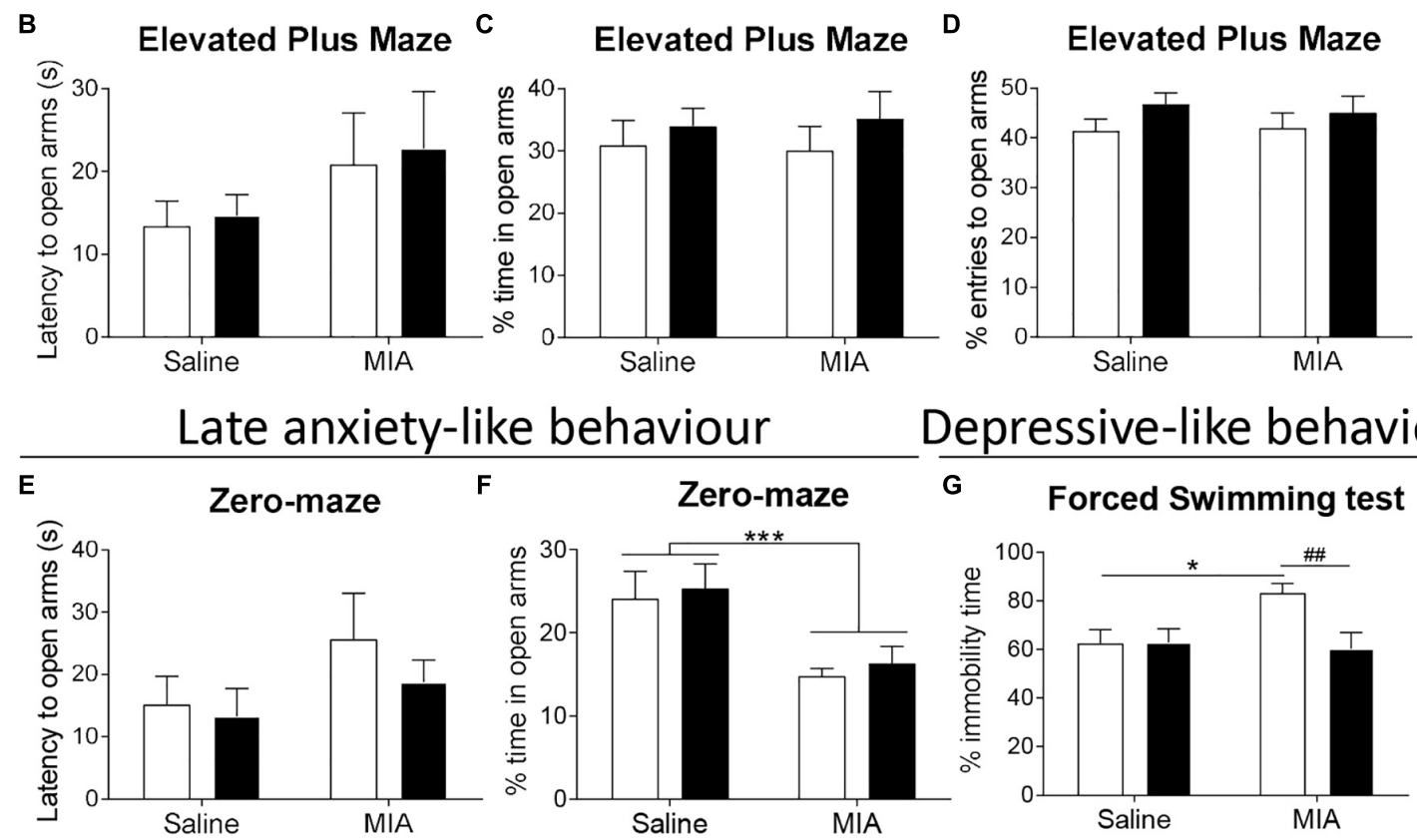

\section{ke behaviour}

F

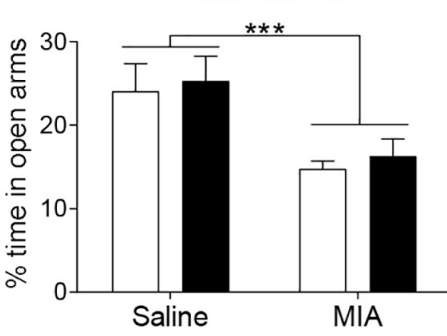

Depressive-like behaviour

G

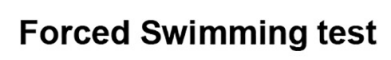

FIGURE 4 | E-52862 treatment reduced depressive-like behavior, but not anxiety-like responses associated with chronic osteoarthritis pain. (A) Emotional manifestations of osteoarthritis pain were assessed in saline- or MIA-injected mice after repeated administration with vehicle or E-52862 (20 mg/kg, twice daily during 25 days) to saline or MIA-injected mice. Anxiety-like behavior was evaluated on day 11 after the intra-knee injection with the elevated plus maze (EPM), and at day 21 in the zero-maze (Z-maze), while depressive-like behavior was determined in the forced-swimming test (FST) on day 25. The latency to enter in the open arms (B), and the percentage of time (C) and entries (D) to the open arms of the EPM showed no significant differences between groups. At day 21, no significant differences were observed in the latency to the open quadrants of the zero-maze (E), whereas mice injected with MIA and treated with vehicle spent less time in the open parts (F). This increase on late anxiety-like behavior was not modified by E-52862 treatment. (G) Mice with osteoarthritis pain receiving vehicle showed increased immobility time, which was reversed by E-52862 treatment. Data are expressed as mean \pm SEM $(n=6-8$ animals per group). For (D): $* * * p<0.001$ for saline vs. MIA (two-way ANOVA). For (E): * $p<0.05$ for saline - vehicle vs. MIA - vehicle, \#\# $p<0.01$ for MIA - vehicle vs. MIA - E-52862 (two-way ANOVA). MIA, monosodium iodoacetate; SEM, standard error of the mean.

chronic pain model. Such correlation has also been described in higher order mammals with osteoarthritis pain (Haussler et al., 2007; Frost-Christensen et al., 2008; Moreau et al., 2011; Cake et al., 2013). Thus, the reduction of the paw print area and the maximal contact area parameters observed in our study in osteoarthritic mice were probably a consequence of an unwillingness of the animal to bear weight on the injured limb, while the normalization of such parameters after E-52862 treatment might be related to reduced pain perception. In agreement, the effect of E-52862 on the walking patterns of mice with osteoarthritis was not accompanied by a normalization of the structural alterations observed in the histological assessments. This absence of effect on cartilage damage is in agreement with the low expression levels of $\sigma 1 \mathrm{R}$ in chondrocytes and bone marrow when compared to its expression in the peripheral and central nervous system ${ }^{1,2}$. The relief of mechanical hypersensitivity and pain-associated comorbidities after the treatment with E-52862 coexisted with the cartilage degradation, in agreement with the widely recognized fact that the presence and severity of joint pain poorly correlates with structural joint damage in osteoarthritis patients (Lawrence et al., 1966; Dieppe, 2004). Thus, the pain-relieving 

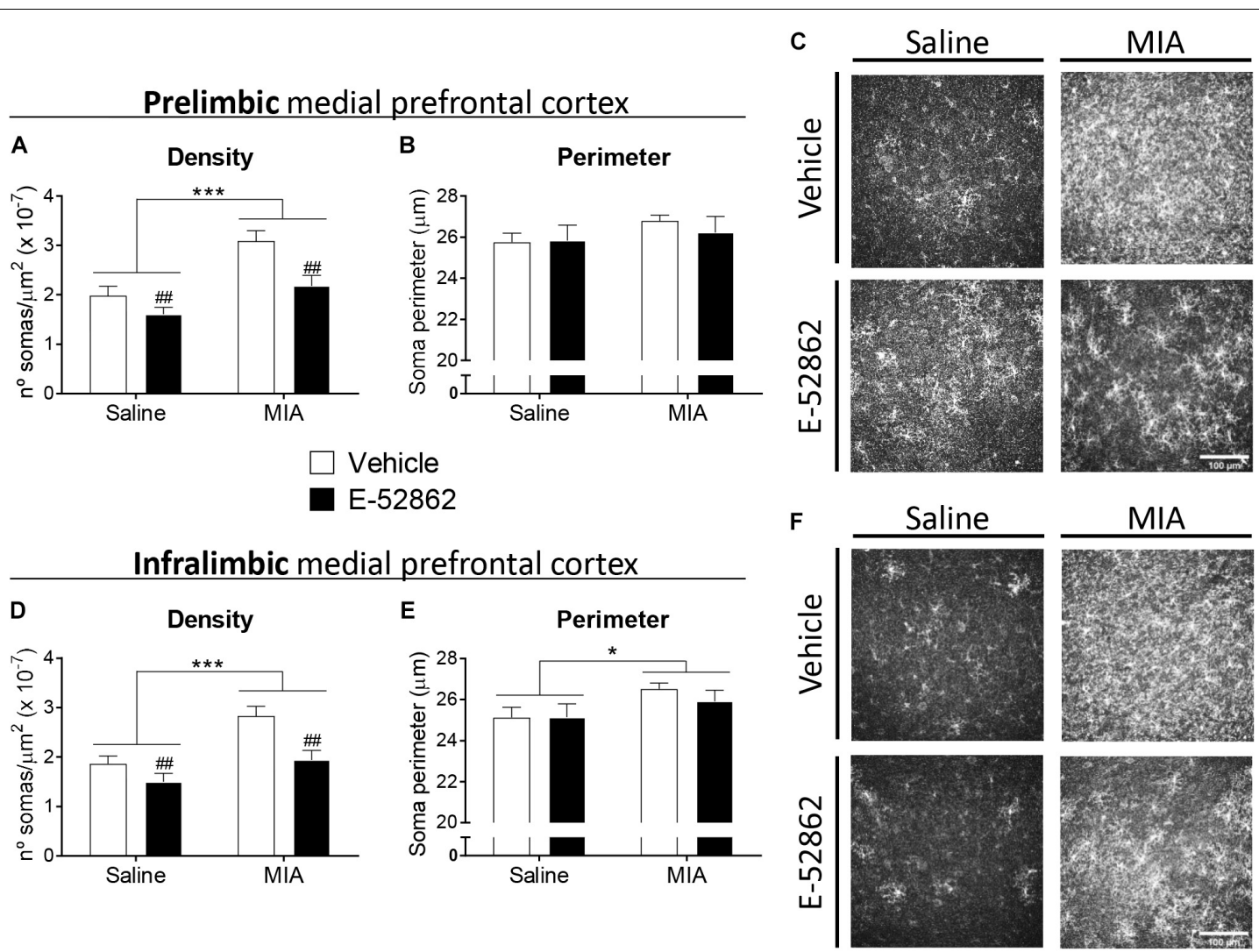

FIGURE 5 | E-52862 decreased pain-induced microgliosis in the medial prefrontal cortex. Microglial cells were detected in the prelimbic and infralimbic areas of the medial prefrontal cortex (mPFC) of saline and MIA injected mice after the repeated treatment with vehicle or the $\sigma 1 \mathrm{R}$ antagonist E-52862 (20 mg/kg, twice daily during 25 days). Mice with osteoarthritis pain treated with vehicle showed an increased density of microglial cells in the prelimbic (A) and the infralimbic areas (D). This microgliosis was normalized by the treatment with E-52862 (A,D). MIA-injected mice revealed larger perimeters of the soma of microglial cells in the infralimbic (E), but not in the prelimbic area (B). Treatment with E-52862 did not modify this alteration (E). (C,F) Representative images of all groups are shown. Data are expressed as the mean \pm SEM ( $n=7$ animals per group). Scale bar: $100 \mu \mathrm{m} .{ }^{*} p<0.05,{ }^{* * *} p<0.001$ for saline vs. MIA, $\# \#<0.01$ for vehicle vs. E-52862 (two-way ANOVA). MIA, monosodium iodoacetate; SEM, standard error of the mean.

effects of the $\sigma 1 \mathrm{R}$ antagonist probably rely on a modulatory role on the nervous system and are independent of the site of the primary lesion.

We observed a cognitive deficit associated to osteoarthritis induced by MIA, which was significantly reduced by the repeated administration of E-52862. Our result suggests that the blockade of $\sigma 1 \mathrm{R}$ plays a protective role in this long-term memory impairment produced by chronic pain. Previous studies also showed impaired memory function in other chronic pain models (Zhao et al., 2006; Kodama et al., 2011) and specifically during MIA-induced joint pain (La Porta et al., 2015; Negrete et al., 2017). Selective $\sigma 1 \mathrm{R}$ ligands failed to modify learning, consolidation or retention phases of the mnemonic process when administered to naive animals (Hashimoto et al., 2007; Antonini et al., 2011), but $\sigma 1 \mathrm{R}$ activation reduced cognitive deficits associated with schizophrenia (Hashimoto et al., 2007), Alzheimer disease (Maurice et al., 1998; Antonini et al., 2011) or scopolamine treatment (Hiramatsu et al., 2002). In contrast, we observed that $\sigma 1 \mathrm{R}$ blockade reversed the memory impairment induced after MIA injection. The overlap between the neuroanatomical substrates implicated in both pain control and cognitive functions provides information about the development of memory deficits in patients with chronic pain (Moriarty et al., 2011). However, the precise causal mechanisms underlying the pain-related cognitive impairment are still unclear, and the role of the $\sigma 1 \mathrm{R}$ on this specific type of memory deficits has not been studied. Our data suggest that $\sigma 1 \mathrm{R}$ antagonists are efficient improving cognitive functions under a chronic pain state.

We obtained increased anxiety-like responses after the intra-knee injection of MIA, as previously reported in other murine models of inflammatory (Schellinck et al., 2003; Chen et al., 2013) and neuropathic pain (Benbouzid et al., 2008; Matsuzawa-Yanagida et al., 2008; La Porta et al., 2016). Anxiety-like behavior was present 3 weeks after MIA, but not at earlier time points (11 days). Previous studies suggested that persistent pain may trigger alterations in brain areas involved in affective responses, which over time may lead to emotional comorbidities including anxiety and depressive-like behavior (Narita et al., 2006; Suzuki et al., 2007; 
Seminowicz et al., 2009; Sellmeijer et al., 2018). In agreement, 25 days after the intra-knee injection of MIA depressivelike responses were observed in animals with osteoarthritis pain, as in previous studies investigating inflammatory and neuropathic pain (Hasnie et al., 2007; Suzuki et al., 2007; Norman et al., 2010; Negrete et al., 2017). Depressivelike responses were abolished after chronic administration of E-52862, although anxiety-like behavior was not modified with this $\sigma 1 \mathrm{R}$ antagonist. These results are in line with previous works studying affective behavior in $\sigma 1 \mathrm{R}$ knockout mice. In these studies, $\sigma 1 \mathrm{R}$ knockouts exhibited increased immobility in the forced swimming test, but normal anxietylike behavior (Sabino et al., 2009), suggesting distinct roles of the receptor modulating depressive and anxiety responses. Common neuroplastic changes associated with chronic pain and emotional disorders were proposed as important routes for the onset and reciprocal aggravation of both pathologies (Sheng et al., 2017). Consequently, analgesic drugs such as opioids (Mague et al., 2003; Tenore, 2008) or benzodiazepines (Vollenweider et al., 2011) have been proposed as a treatment for chronic pain-induced depression, and antidepressants like selective serotonin reuptake inhibitors (SSRIs) (Tasmuth et al., 2002; Gebhardt et al., 2016) or tricyclic antidepressants (Rowbotham et al., 2005; Kopsky and Keppel Hesselink, 2012) exhibited antinociceptive effects under chronic pain conditions. The interest of $\sigma 1 \mathrm{R}$ ligands for the treatment of depressive states raised from the observation that several antidepressants had moderate to high affinity for $\sigma 1 \mathrm{R}$ sites (Schmidt et al., 1989; Itzhak et al., 1991; Narita et al., 1996). While some SSRIs such as fluvoxamine or venlafaxine have shown agonism for $\sigma 1 \mathrm{R}$, others like sertraline may act as antagonists (Ishima et al., 2014). Moreover, the antidepressant efficacy of $\sigma 1 \mathrm{R}$ ligands may depend on the affective status of the animal, since the selective $\sigma 1 \mathrm{R}$ agonist PRE-084 reduced depressive-like behavior in adrenalectomized mice but lacked effect in naïve animals (Urani et al., 2001).

We observed an increased microgliosis in the medial prefrontal cortex produced by the injection of MIA. This result agrees with a previous study showing increases of microglial density in the infralimbic cortex of nerve-injured rats (Chu Sin Chung et al., 2017; Xu et al., 2017). Other brain areas such as the amygdala, periaqueductal gray (PAG) or hippocampus, have also shown increased gliosis during chronic pain conditions (Humo et al., 2019). Interestingly, a recent study on neuropathic pain showed enhanced expression of microglial markers in the prefrontal cortex accompanied by depressive-like behavior. Chronic minocycline attenuated both microglial activation and depressive-like responses (Xu et al., 2017). Previous studies have shown that the $\sigma 1 \mathrm{R}$ antagonist BD1047 attenuated microglial activation in the spinal cord in a model of bone cancer pain (Zhu et al., 2015), but the effect of $\sigma 1 \mathrm{R}$ on supraspinal microglia has not been assessed in chronic pain models. Our data show that $\sigma 1 \mathrm{R}$ antagonist E-52862 significantly reduced the density of microglia in medial prefrontal cortices of mice with osteoarthritis pain. This effect was not accompanied by a reduction of anxiety-like behavior, suggesting that this affective disturbance is not directly related to cortical microgliosis. However, these anatomical changes correlated with the cognitive performance and the depressive-like behavior, pointing toward an involvement of cortical microglia on both pain comorbidities. Therefore, $\sigma 1 \mathrm{R}$-regulated cortical microgliosis might be crucial for the manifestation of cognitive and emotional alterations often present in chronic pain conditions. Indeed, antidepressant drugs such as SSRIs also have activity modulating microgliosis and reducing microglial production of tumor necrosis factor $\alpha$ and nitric oxide (Chung et al., 2011; Tynan et al., 2012). It is well known that $\sigma 1 \mathrm{R}$ modulates several signal transduction pathways, including the production of ATP, reactive oxygen species or mitogenactivated protein kinases (MAPK) (Zamanillo et al., 2013; Hayashi, 2015; Zhao et al., 2017). All these molecules have been identified as effective signals for microglial migration and activation (Biber et al., 2007; Fan et al., 2017), suggesting an indirect modulatory role of $\sigma 1 \mathrm{R}$. In agreement, $\sigma 1 \mathrm{R}$ activation by methamphetamine induces a microgliosis that involves generation of reactive oxygen species and activation of the MAPK pathway (Chao et al., 2017).

The present study reveals that E-52862 alleviates the nociceptive, cognitive and emotional manifestations associated to chronic osteoarthritis pain. We provide evidence showing that the effect of $\sigma 1 \mathrm{R}$ over these manifestations of chronic pain is not associated to local changes in articular damage but is accompanied by modulation of microglial activity in the medial prefrontal cortex. Our data highlight the blockade of $\sigma 1 \mathrm{R}$ as an interesting pharmacological strategy for the simultaneous management of multiple aspects of chronic osteoarthritis pain.

\section{ETHICS STATEMENT}

All experimental procedures and animal husbandry were conducted following the ARRIVE (Animal Research: Reporting In Vivo Experiments) guidelines and according to the ethical principles of the International Association for the Study of Pain (I.A.S.P.) for the evaluation of pain in conscious animals (Zimmermann, 1986) and the European Parliament and the Council Directive (2010/63/EU), and were approved by the Animal Care and Use Committees of the PRBB and Departament de Territori i Habitatge of Generalitat de Catalunya.

\section{AUTHOR CONTRIBUTIONS}

All authors listed have made a substantial, direct and intellectual contribution to the work, and approved it for publication.

\section{ACKNOWLEDGMENTS}

We acknowledge the financial support of the European Commission (FP7, NeuroPain \#2013-602891), the Catalan Government (AGAUR, \#SGR2017-669), the Spanish Instituto 
de Salud Carlos III (RTA, \#RD16/0017/0020), and AGAUR (ICREA Academia Award 2015). MC is the recipient of an Industrial Doctorate contract from the Catalan Government and Laboratorios Esteve (AGAUR, \#2014-DI-040). Partial support from FEDER funds is also acknowledged.

\section{REFERENCES}

Alonso, G., Phan, V., Guillemain, I., Saunier, M., Legrand, A., Anoal, M., et al. (2000). Immunocytochemical localization of the sigma(1) receptor in the adult rat central nervous system. Neuroscience 97, 155-170. doi: 10.1016/s03064522(00)00014-2

Antonini, V., Marrazzo, A., Kleiner, G., Coradazzi, M., Ronsisvalle, S., Prezzavento, O., et al. (2011). Anti-amnesic and neuroprotective actions of the sigma-1 receptor agonist (-)-MR22 in rats with selective cholinergic lesion and amyloid infusion. J. Alzheimers Dis. 24, 569-586. doi: 10.3233/JAD-2011-101794

Apkarian, A. V., Bushnell, M. C., Treede, R.-D., and Zubieta, J.-K. (2005). Human brain mechanisms of pain perception and regulation in health and disease. Eur. J. Pain 9, 463-463. doi: 10.1016/j.ejpain.2004.11.001

Apkarian, A. V., Sosa, Y., Sonty, S., Levy, R. M., Harden, R. N., Parrish, T. B., et al. (2004). Chronic back pain is associated with decreased prefrontal and thalamic gray matter density. J. Neurosci. 24, 10410-10415. doi: 10.1523/JNEUROSCI. 2541-04.2004

Axford, J., Butt, A., Heron, C., Hammond, J., Morgan, J., Alavi, A., et al. (2010). Prevalence of anxiety and depression in osteoarthritis: use of the hospital anxiety and depression scale as a screening tool. Clin. Rheumatol. 29, 1277-1283. doi: 10.1007/s10067-010-1547-7

Bangaru, M. L., Weihrauch, D., Tang, Q.-B., Zoga, V., Hogan, Q., and Wu, H. (2013). Sigma-1 receptor expression in sensory neurons and the effect of painful peripheral nerve injury. Mol. Pain 9:47. doi: 10.1186/1744-8069-9-47

Benbouzid, M., Pallage, V., Rajalu, M., Waltisperger, E., Doridot, S., Poisbeau, P., et al. (2008). Sciatic nerve cuffing in mice: a model of sustained neuropathic pain. Eur. J. Pain 12, 591-599. doi: 10.1016/j.ejpain.2007.10.002

Biber, K., Neumann, H., Inoue, K., and Boddeke, H. W. G. M. (2007). Neuronal "On" and "Off" signals control microglia. Trends Neurosci. 30, 596-602. doi: 10.1016/j.tins.2007.08.007

Boadas-Vaello, P., Homs, J., Reina, F., Carrera, A., and Verdú, E. (2017). Neuroplasticity of supraspinal structures associated with pathological pain. Anat. Rec. 300, 1481-1501. doi: 10.1002/ar.23587

Boettger, M. K., Weber, K., Schmidt, M., Gajda, M., Bräuer, R., and Schaible, H.-G. (2009). Gait abnormalities differentially indicate pain or structural joint damage in monoarticular antigen-induced arthritis. Pain 145, 142-150. doi: 10.1016/j.pain.2009.06.006

Cake, M. A., Read, R. A., Corfield, G., Daniel, A., Burkhardt, D., Smith, M. M., et al. (2013). Comparison of gait and pathology outcomes of three meniscal procedures for induction of knee osteoarthritis in sheep. Osteoarthr. Cartil. 21, 226-236. doi: 10.1016/j.joca.2012.10.001

Castany, S., Gris, G., Vela, J. M., Verdú, E., and Boadas-Vaello, P. (2018). Critical role of sigma-1 receptors in central neuropathic pain-related behaviours after mild spinal cord injury in mice. Sci. Rep. 8:3873. doi: 10.1038/s41598-01822217-9

Chao, J., Zhang, Y., Du, L., Zhou, R., Wu, X., Shen, K., et al. (2017). Molecular mechanisms underlying the involvement of the sigma-1 receptor in methamphetamine-mediated microglial polarization. Sci. Rep. 7:11540. doi: 10.1038/s41598-017-11065-8

Chaplan, S. R., Bach, F. W., Pogrel, J. W., Chung, J. M., and Yaksh, T. L. (1994). Quantitative assessment of tactile allodynia in the rat paw. J. Neurosci. Methods 53, 55-63. doi: 10.1016/0165-0270(94)90144-9

Chen, J., Song, Y., Yang, J., Zhang, Y., Zhao, P., Zhu, X.-J., et al. (2013). The contribution of TNF- $\alpha$ in the amygdala to anxiety in mice with persistent inflammatory pain. Neurosci. Lett. 541, 275-280. doi: 10.1016/j.neulet.2013.0 2.005

Chu Sin, Chung, P., Panigada, T., Cardis, R., Decosterd, I., and Gosselin, R.-D. (2017). Peripheral nerve injury induces a transitory microglial reaction in the rat infralimbic cortex. Neurosci. Lett. 655, 14-20. doi: 10.1016/j.neulet.2017.0 6.037

\section{SUPPLEMENTARY MATERIAL}

The Supplementary Material for this article can be found online at: https://www.frontiersin.org/articles/10.3389/fphar. 2019.00468/full\#supplementary-material

Chung, Y. C., Kim, S. R., Park, J.-Y., Chung, E. S., Park, K. W., Won, S. Y., et al. (2011). Fluoxetine prevents MPTP-induced loss of dopaminergic neurons by inhibiting microglial activation. Neuropharmacology 60, 963-974. doi: 10.1016/ j.neuropharm.2011.01.043

Cruz, A. P., Frei, F., and Graeff, F. G. (1994). Ethopharmacological analysis of rat behavior on the elevated plus-maze. Pharmacol. Biochem. Behav. 49, 171-176. doi: 10.1016/0091-3057(94)90472-3

Dieppe, P. A. (2004). Relationship between symptoms and structural change in osteoarthritis. What are the important targets for osteoarthritis therapy? J. Rheumatol. Suppl. 70, 50-53.

Dixon, W. J. (1965). The up-and-down method for small samples. J. Am. Stat. Assoc. 60, 967-978. doi: 10.1080/01621459.1965.10480843

Entrena, J. M., Cobos, E. J., Nieto, F. R., Cendán, C. M., Gris, G., Del Pozo, E., et al. (2009). Sigma-1 receptors are essential for capsaicin-induced mechanical hypersensitivity: Studies with selective sigma-1 ligands and sigma-1 knockout mice. Pain 143, 252-261. doi: 10.1016/j.pain.2009.03.011

Etkin, A., Egner, T., and Kalisch, R. (2011). Emotional processing in anterior cingulate and medial prefrontal cortex. Trends Cogn. Sci. 15, 85-93. doi: 10.1016/j.tics.2010.11.004

Fan, Y., Xie, L., and Chung, C. Y. (2017). Signaling pathways controlling microglia chemotaxis. Mol. Cells 40, 163-168. doi: 10.14348/molcells.2017.0011

Ferland, C. E., Laverty, S., Beaudry, F., and Vachon, P. (2011). Gait analysis and pain response of two rodent models of osteoarthritis. Pharmacol. Biochem. Behav. 97, 603-610. doi: 10.1016/j.pbb.2010.11.003

Ferreira-Gomes, J., Adães, S., Mendonça, M., and Castro-Lopes, J. M. (2012). Analgesic effects of lidocaine, morphine and diclofenac on movement-induced nociception, as assessed by the knee-bend and cat walk tests in a rat model of osteoarthritis. Pharmacol. Biochem. Behav. 101, 617-624. doi: 10.1016/j.pbb. 2012.03.003

File, S. E., Mabbutt, P. S., and Hitchcott, P. K. (1990). Characterisation of the phenomenon of \&qout;one-trial tolerance\&qout; to the anxiolytic effect of chlordiazepoxide in the elevated plus-maze. Psychopharmacology 102, 98-101. doi: $10.1007 / \mathrm{bf02245751}$

Francardo, V., Bez, F., Wieloch, T., Nissbrandt, H., Ruscher, K., and Cenci, M. A. (2014). Pharmacological stimulation of sigma-1 receptors has neurorestorative effects in experimental parkinsonism. Brain 137, 1998-2014. doi: 10.1093/ brain/awu107

Frost-Christensen, L. N., Mastbergen, S. C., Vianen, M. E., Hartog, A., DeGroot, J., Voorhout, G., et al. (2008). Degeneration, inflammation, regeneration, and pain/disability in dogs following destabilization or articular cartilage grooving of the stifle joint. Osteoarthr. Cartil. 16, 1327-1335. doi: 10.1016/j.joca.2008.0 3.013

Gebhardt, S., Heinzel-Gutenbrunner, M., and König, U. (2016). Pain relief in depressive disorders. J. Clin. Psychopharmacol. 36, 658-668. doi: 10.1097/JCP. 0000000000000604

Gekker, G., Hu, S., Sheng, W. S., Rock, R. B., Lokensgard, J. R., and Peterson, P. K. (2006). Cocaine-induced HIV-1 expression in microglia involves sigma1 receptors and transforming growth factor-betal. Int. Immunopharmacol. 6, 1029-1033. doi: 10.1016/j.intimp.2005.12.005

Glasson, S. S., Chambers, M. G., Van Den Berg, W. B., and Little, C. B. (2010). The OARSI histopathology initiative - recommendations for histological assessments of osteoarthritis in the mouse. Osteoarthr. Cartil. 18, S17-S23. doi: 10.1016/j.joca.2010.05.025

Goldenberg, D. L. (2010). The interface of pain and mood disturbances in the rheumatic diseases. Semin. Arthritis Rheum. 40, 15-31. doi: 10.1016/j. semarthrit.2008.11.005

Gris, G., Merlos, M., Vela, J. M., Zamanillo, D., and Portillo-Salido, E. (2014). S1RA, a selective sigma-1 receptor antagonist, inhibits inflammatory pain in the carrageenan and complete Freund's adjuvant models in mice. Behav. Pharmacol. 25, 226-235. doi: 10.1097/FBP.0000000000000038 
Gris, G., Portillo-Salido, E., Aubel, B., Darbaky, Y., Deseure, K., Vela, J. M., et al. (2016). The selective sigma-1 receptor antagonist E-52862 attenuates neuropathic pain of different aetiology in rats. Sci. Rep. 6:24591. doi: 10.1038/ srep24591

Gusnard, D. A., Akbudak, E., Shulman, G. L., and Raichle, M. E. (2001). Medial prefrontal cortex and self-referential mental activity: Relation to a default mode of brain function. Proc. Natl. Acad. Sci. U.S.A. 98, 4259-4264. doi: 10.1073/pnas. 071043098

Harada, Y., Hara, H., and Sukamoto, T. (1994). Receptor binding profiles of KB5492, a novel anti-ulcer agent, at sigma receptors in guinea-pig brain. Eur. J. Pharmacol. 256, 321-328. doi: 10.1016/0014-2999(94)90558-4

Hashimoto, K., Fujita, Y., and Iyo, M. (2007). Phencyclidine-induced cognitive deficits in mice are improved by subsequent subchronic administration of fluvoxamine: role of sigma-1 receptors. Neuropsychopharmacology 32, 514-521. doi: 10.1038/sj.npp.1301047

Hasnie, F. S., Wallace, V. C. J., Hefner, K., Holmes, A., and Rice, A. S. C. (2007). Mechanical and cold hypersensitivity in nerve-injured C57BL/6J mice is not associated with fear-avoidance- and depression-related behaviour. $\mathrm{Br}$. J. Anaesth. 98, 816-822. doi: 10.1093/bja/aem087

Haussler, K. K., Hill, A. E., Frisbie, D. D., and McIlwraith, C. W. (2007). Determination and use of mechanical nociceptive thresholds of the thoracic limb to assess pain associated with induced osteoarthritis of the middle carpal joint in horses. Am. J. Vet. Res. 68, 1167-1176. doi: 10.2460/ajvr.68.11.1167

Hayashi, T. (2015). Sigma-1 receptor: the novel intracellular target of neuropsychotherapeutic drugs. J. Pharmacol. Sci. 127, 2-5. doi: 10.1016/J.JPHS.2014.07.001

Hayashi, T., and Su, T.-P. (2007). Sigma-1 receptor chaperones at the ERmitochondrion interface regulate $\mathrm{Ca}(2+)$ signaling and cell survival. Cell 131, 596-610. doi: 10.1016/j.cell.2007.08.036

Hayashi, T., Tsai, S.-Y., Mori, T., Fujimoto, M., and Su, T.-P. (2011). Targeting ligand-operated chaperone sigma-1 receptors in the treatment of neuropsychiatric disorders. Expert Opin. Ther. Targets 15, 557-577. doi: 10.1517/14728222.2011.560837

Hiramatsu, M., Hoshino, T., Kameyama, T., and Nabeshima, T. (2002). Involvement of kappa-opioid and sigma receptors in short-term memory in mice. Eur. J. Pharmacol. 453, 91-98. doi: 10.1016/s0014-2999(02)02388-9

Holmes, A., and Rodgers, R. J. (1998). Responses of swiss-webster mice to repeated plus-maze experience: further evidence for a qualitative shift in emotional state? Pharmacol. Biochem. Behav. 60, 473-488. doi: 10.1016/s0091-3057(98)00008-2

Humo, M., Lu, H., and Yalcin, I. (2019). The molecular neurobiology of chronic pain-induced depression. Cell Tissue Res. [Epub ahead of print].

Ishima, T., Fujita, Y., and Hashimoto, K. (2014). Interaction of new antidepressants with sigma-1 receptor chaperones and their potentiation of neurite outgrowth in PC12 cells. Eur. J. Pharmacol. 727, 167-173. doi: 10.1016/j.ejphar.2014.0 1.064

Itzhak, Y., Stein, I., Zhang, S. H., Kassim, C. O., and Cristante, D. (1991). Binding of sigma-ligands to C57BL/6 mouse brain membranes: effects of monoamine oxidase inhibitors and subcellular distribution studies suggest the existence of sigma-receptor subtypes. J. Pharmacol. Exp. Ther. 257, 141-148.

Johnson, V. L., and Hunter, D. J. (2014). The epidemiology of osteoarthritis. Best Pract. Res. Clin. Rheumatol. 28, 5-15. doi: 10.1016/j.berh.2014.01.004

Kitaichi, K., Chabot, J. G., Moebius, F. F., Flandorfer, A., Glossmann, H., and Quirion, R. (2000). Expression of the purported sigma(1) (sigma(1)) receptor in the mammalian brain and its possible relevance in deficits induced by antagonism of the NMDA receptor complex as revealed using an antisense strategy. J. Chem. Neuroanat. 20, 375-387. doi: 10.1016/s0891-0618(00)00 106-x

Kodama, D., Ono, H., and Tanabe, M. (2011). Increased hippocampal glycine uptake and cognitive dysfunction after peripheral nerve injury. Pain 152, 809-817. doi: 10.1016/j.pain.2010.12.029

Kopsky, D. J., and Keppel Hesselink, J. M. (2012). High doses of topical amitriptyline in neuropathic pain: two cases and literature review. Pain Pract. 12, 148-153. doi: 10.1111/j.1533-2500.2011.00477.x

La Porta, C., Bura, S. A., Llorente-Onaindia, J., Pastor, A., Navarrete, F., GarcíaGutiérrez, M. S., et al. (2015). Role of the endocannabinoid system in the emotional manifestations of osteoarthritis pain. Pain 156, 2001-2012. doi: 10. 1097/j.pain.0000000000000260
La Porta, C., Lara-Mayorga, I. M., Negrete, R., and Maldonado, R. (2016). Effects of pregabalin on the nociceptive, emotional and cognitive manifestations of neuropathic pain in mice. Eur. J. Pain 20, 1454-1466. doi: 10.1002/ejp.868

Lawrence, J. S., Bremner, J. M., and Bier, F. (1966). Osteo-arthrosis. Prevalence in the population and relationship between symptoms and x-ray changes. Ann. Rheum. Dis. 25, 1-24. doi: 10.1136/annrheumd00506-0006

Lucas, G., Rymar, V. V., Sadikot, A. F., and Debonnel, G. (2008). Further evidence for an antidepressant potential of the selective sigmal agonist SA 4503: electrophysiological, morphological and behavioural studies. Int. J. Neuropsychopharmacol. 11, 485-495. doi: 10.1017/S1461145708008547

Mague, S. D., Pliakas, A. M., Todtenkopf, M. S., Tomasiewicz, H. C., Zhang, Y., Stevens, W. C., et al. (2003). Antidepressant-like effects of kappa -opioid receptor antagonists in the forced swim test in rats. J. Pharmacol. Exp. Ther. 305, 323-330. doi: 10.1124/jpet.102.046433

Matsumoto, R. R., McCracken, K. A., Pouw, B., Zhang, Y., and Bowen, W. D. (2002). Involvement of sigma receptors in the behavioral effects of cocaine: evidence from novel ligands and antisense oligodeoxynucleotides. Neuropharmacology 42, 1043-1055. doi: 10.1016/s0028-3908(02)00056-4

Matsuzawa-Yanagida, K., Narita, M., Nakajima, M., Kuzumaki, N., Niikura, K., Nozaki, H., et al. (2008). Usefulness of antidepressants for improving the neuropathic pain-like state and pain-induced anxiety through actions at different brain sites. Neuropsychopharmacology 33, 1952-1965. doi: 10.1038/sj. npp. 1301590

Maurice, T., Martin-Fardon, R., Romieu, P., and Matsumoto, R. R. (2002). Sigma(1) (sigma(1)) receptor antagonists represent a new strategy against cocaine addiction and toxicity. Neurosci. Biobehav. Rev. 26, 499-527. doi: 10.1016/s0149-7634(02)00017-9

Maurice, T., Su, T. P., and Privat, A. (1998). Sigmal (sigma 1) receptor agonists and neurosteroids attenuate B25-35-amyloid peptide-induced amnesia in mice through a common mechanism. Neuroscience 83, 413-428. doi: 10.1016/s03064522(97)00405-3

Metz, A. E., Yau, H.-J., Centeno, M. V., Apkarian, A. V., and Martina, M. (2009). Morphological and functional reorganization of rat medial prefrontal cortex in neuropathic pain. Proc. Natl. Acad. Sci. U.S.A. 106, 2423-2428. doi: 10.1073/ pnas.0809897106

Moreau, M., Rialland, P., Pelletier, J.-P., Martel-Pelletier, J., Lajeunesse, D., Boileau, C., et al. (2011). Tiludronate treatment improves structural changes and symptoms of osteoarthritis in the canine anterior cruciate ligament model. Arthritis Res. Ther. 13:R98. doi: 10.1186/ar3373

Moriarty, O., and Finn, D. P. (2014). Cognition and pain. Curr. Opin. Support. Palliat. Care 8, 130-136. doi: 10.1097/SPC.0000000000000054

Moriarty, O., McGuire, B. E., and Finn, D. P. (2011). The effect of pain on cognitive function: A review of clinical and preclinical research. Prog. Neurobiol. 93, 385-404. doi: 10.1016/j.pneurobio.2011.01.002

Moritz, C., Berardi, F., Abate, C., and Peri, F. (2015). Live imaging reveals a new role for the sigma-1 $(\sigma 1)$ receptor in allowing microglia to leave brain injuries. Neurosci. Lett. 591, 13-18. doi: 10.1016/j.neulet.2015.02.004

Narita, M., Kuzumaki, N., Narita, M., Kaneko, C., Hareyama, N., Miyatake, M., et al. (2006). Chronic pain-induced emotional dysfunction is associated with astrogliosis due to cortical delta-opioid receptor dysfunction. J. Neurochem. 97, 1369-1378. doi: 10.1111/j.1471-4159.2006.03824.x

Narita, N., Hashimoto, K., Tomitaka, S., and Minabe, Y. (1996). Interactions of selective serotonin reuptake inhibitors with subtypes of sigma receptors in rat brain. Eur. J. Pharmacol. 307, 117-119. doi: 10.1016/0014-2999(96)00 254-3

Negrete, R., García Gutiérrez, M. S., Manzanares, J., and Maldonado, R. (2017). Involvement of the dynorphin/KOR system on the nociceptive, emotional and cognitive manifestations of joint pain in mice. Neuropharmacology 116, 315-327. doi: 10.1016/j.neuropharm.2016.08.026

Nieto, F. R., Cendán, C. M., Sánchez-Fernández, C., Cobos, E. J., Entrena, J. M., Tejada, M. A., et al. (2012). Role of sigma-1 receptors in paclitaxel-induced neuropathic pain in mice. J. Pain 13, 1107-1121. doi: 10.1016/j.jpain.2012.0 8.006

Norman, G. J., Karelina, K., Zhang, N., Walton, J. C., Morris, J. S., and DeVries, A. C. (2010). Stress and IL-1 $\beta$ contribute to the development of depressivelike behavior following peripheral nerve injury. Mol. Psychiatry 15, 404-414. doi: $10.1038 / \mathrm{mp} .2009 .91$ 
Panigada, T., and Gosselin, R.-D. (2011). Behavioural alteration in chronic pain: Are brain glia involved? Med. Hypotheses 77, 584-588. doi: 10.1016/j.mehy. 2011.06.036

Peviani, M., Salvaneschi, E., Bontempi, L., Petese, A., Manzo, A., Rossi, D., et al. (2014). Neuroprotective effects of the Sigma-1 receptor (S1R) agonist PRE084, in a mouse model of motor neuron disease not linked to SOD1 mutation. Neurobiol. Dis. 62, 218-232. doi: 10.1016/j.nbd.2013.10.010

Phelps, E. A., Delgado, M. R., Nearing, K. I., and LeDoux, J. E. (2004). Extinction learning in humans. Neuron 43, 897-905. doi: 10.1016/j.neuron.2004.0 8.042

Porsolt, R. D., Bertin, A., and Jalfre, M. (1977). Behavioral despair in mice: a primary screening test for antidepressants. Arch. Int. Pharmacodyn. Ther. 229, 327-336.

Puighermanal, E., Marsicano, G., Busquets-Garcia, A., Lutz, B., Maldonado, R., and Ozaita, A. (2009). Cannabinoid modulation of hippocampal longterm memory is mediated by mTOR signaling. Nat. Neurosci. 12, 1152-1158. doi: $10.1038 / \mathrm{nn} .2369$

Puig-Junoy, J., and Ruiz Zamora, A. (2015). Socio-economic costs of osteoarthritis: a systematic review of cost-of-illness studies. Semin. Arthritis Rheum. 44, 531-541. doi: 10.1016/j.semarthrit.2014.10.012

Racz, I., Nadal, X., Alferink, J., Banos, J. E., Rehnelt, J., Martin, M., et al. (2008). Crucial role of CB2 cannabinoid receptor in the regulation of central immune responses during neuropathic pain. J. Neurosci. 28, 12125-12135. doi: 10.1523/ JNEUROSCI.3400-08.2008

Romero, L., Zamanillo, D., Nadal, X., Sánchez-Arroyos, R., Rivera-Arconada, I., Dordal, A., et al. (2012). Pharmacological properties of S1RA, a new sigma-1 receptor antagonist that inhibits neuropathic pain and activity-induced spinal sensitization. Br. J. Pharmacol. 166, 2289-2306. doi: 10.1111/j.1476-5381.2012. 01942.x

Rowbotham, M. C., Reisner, L. A., Davies, P. S., and Fields, H. L. (2005). Treatment response in antidepressant-naïve postherpetic neuralgia patients: double-blind, randomized trial. J. Pain 6, 741-746. doi: 10.1016/j.jpain.2005.0 7.001

Sabino, V., Cottone, P., Parylak, S. L., Steardo, L., and Zorrilla, E. P. (2009). Sigma1 receptor knockout mice display a depressive-like phenotype. Behav. Brain Res. 198, 472-476. doi: 10.1016/j.bbr.2008.11.036

Saravia, R., Ten-Blanco, M., Grande, M. T., Maldonado, R., and Berrendero, F. (2019). Anti-inflammatory agents for smoking cessation? Focus on cognitive deficits associated with nicotine withdrawal in male mice. Brain. Behav. Immun. 75, 228-239. doi: 10.1016/j.bbi.2018.11.003

Schellinck, H. M., Stanford, L., and Darrah, M. (2003). Repetitive acute pain in infancy increases anxiety but does not alter spatial learning ability in juvenile mice. Behav. Brain Res. 142, 157-165. doi: 10.1016/s0166-4328(02)00 406-0

Schmidt, A., Lebel, L., Koe, B. K., Seeger, T., and Heym, J. (1989). Sertraline potently displaces $(+)-[3 \mathrm{H}] 3-\mathrm{PPP}$ binding to sigma sites in rat brain. Eur. J. Pharmacol. 165, 335-336. doi: 10.1016/0014-2999(89)90 734-6

Sellmeijer, J., Mathis, V., Hugel, S., Li, X.-H., Song, Q., Chen, Q.-Y., et al. (2018). Hyperactivity of anterior cingulate cortex areas $24 \mathrm{a} / 24 \mathrm{~b}$ drives chronic pain-induced anxiodepressive-like consequences. J. Neurosci. 38, 3102-3115. doi: 10.1523/JNEUROSCI.3195-17.2018

Seminowicz, D. A., Laferriere, A. L., Millecamps, M., Yu, J. S. C., Coderre, T. J., and Bushnell, M. C. (2009). MRI structural brain changes associated with sensory and emotional function in a rat model of long-term neuropathic pain. Neuroimage 47, 1007-1014. doi: 10.1016/j.neuroimage.2009.0 5.068

Seminowicz, D. A., Wideman, T. H., Naso, L., Hatami-Khoroushahi, Z., Fallatah, S., Ware, M. A., et al. (2011). Effective treatment of chronic low back pain in humans reverses abnormal brain anatomy and function. J. Neurosci. 31, 7540-7550. doi: 10.1523/JNEUROSCI.5280-10.2011

Sharma, A., Kudesia, P., Shi, Q., and Gandhi, R. (2016). Anxiety and depression in patients with osteoarthritis: impact and management challenges. Open Access Rheumatol. 8, 103-113. doi: 10.2147/OARRR.S93516

Sheng, J., Liu, S., Wang, Y., Cui, R., and Zhang, X. (2017). The link between depression and chronic pain: neural mechanisms in the brain. Neural Plast. 2017:9724371. doi: 10.1155/2017/9724371
Shepherd, J. K., Grewal, S. S., Fletcher, A., Bill, D. J., and Dourish, C. T. (1994). Behavioural and pharmacological characterisation of the elevated \&quot;zeromaze\&quot; as an animal model of anxiety. Psychopharmacology 116, 56-64. doi: 10.1007/bf02244871

Skuza, G., and Rogóz, Z. (2003). Sigmal receptor antagonists attenuate antidepressant-like effect induced by co-administration of 1,3 di-otolylguanidine (DTG) and memantine in the forced swimming test in rats. Pol. J. Pharmacol. 55, 1149-1152.

Su, T.-P., and Hayashi, T. (2003). Understanding the molecular mechanism of sigma-1 receptors: towards a hypothesis that sigma-1 receptors are intracellular amplifiers for signal transduction. Curr. Med. Chem. 10, 2073-2080. doi: 10. 2174/0929867033456783

Sutton, S., Clutterbuck, A., Harris, P., Gent, T., Freeman, S., Foster, N., et al. (2009). The contribution of the synovium, synovial derived inflammatory cytokines and neuropeptides to the pathogenesis of osteoarthritis. Vet. J. 179, 10-24. doi: 10.1016/j.tvjl.2007.08.013

Suzuki, T., Amata, M., Sakaue, G., Nishimura, S., Inoue, T., Shibata, M., et al. (2007). Experimental neuropathy in mice is associated with delayed behavioral changes related to anxiety and depression. Anesth. Analg. 104, 1570-1577. doi: 10.1213/01.ane.0000261514.19946.66

Tasmuth, T., Härtel, B., and Kalso, E. (2002). Venlafaxine in neuropathic pain following treatment of breast cancer. Eur. J. Pain 6, 17-24. doi: 10.1053/eujp. 2001.0266

Tejada, M. A., Montilla-García, A., Sánchez-Fernández, C., Entrena, J. M., Perazzoli, G., Baeyens, J. M., et al. (2014). Sigma-1 receptor inhibition reverses acute inflammatory hyperalgesia in mice: role of peripheral sigma1 receptors. Psychopharmacology 231, 3855-3869. doi: 10.1007/s00213-014-3 524-3

Tenore, P. L. (2008). Psychotherapeutic benefits of opioid agonist therapy. J. Addict. Dis. 27, 49-65. doi: 10.1080/1055088080212 2646

Tsai, S.-Y., Hayashi, T., Mori, T., and Su, T.-P. (2009). Sigma-1 receptor chaperones and diseases. Cent. Nerv. Syst. Agents Med. Chem. 9, 184-189. doi: 10.2174/ 1871524910909030184

Tynan, R. J., Weidenhofer, J., Hinwood, M., Cairns, M. J., Day, T. A., and Walker, F. R. (2012). A comparative examination of the anti-inflammatory effects of SSRI and SNRI antidepressants on LPS stimulated microglia. Brain Behav. Immun. 26, 469-479. doi: 10.1016/j.bbi.2011.12.011

Urani, A., Roman, F. J., Phan, V. L., Su, T. P., and Maurice, T. (2001). The antidepressant-like effect induced by sigma(1)-receptor agonists and neuroactive steroids in mice submitted to the forced swimming test. J. Pharmacol. Exp. Ther. 298, 1269-1279.

Villemure, C., and Bushnell, M. C. (2009). Mood influences supraspinal pain processing separately from attention. J. Neurosci. 29, 705-715. doi: 10.1523/ JNEUROSCI.3822-08.2009

Vollenweider, I., Smith, K. S., Keist, R., and Rudolph, U. (2011). Antidepressantlike properties of $\alpha 2$-containing GABAA receptors. Behav. Brain Res. 217, 77-80. doi: 10.1016/j.bbr.2010.10.009

Vrinten, D. H., and Hamers, F. F. T. (2003). "CatWalk" automated quantitative gait analysis as a novel method to assess mechanical allodynia in the rat; a comparison with von Frey testing. Pain 102, 203-209. doi: 10.1016/s03043959(02)00382-2

Xu, N., Tang, X.-H., Pan, W., Xie, Z.-M., Zhang, G.-F., Ji, M.-H., et al. (2017). Spared nerve injury increases the expression of microglia M1 markers in the prefrontal cortex of rats and provokes depressionlike behaviors. Front. Neurosci. 11:209. doi: 10.3389/fnins.2017.0 0209

Zamanillo, D., Romero, L., Merlos, M., and Vela, J. M. (2013). Sigma 1 receptor: a new therapeutic target for pain. Eur. J. Pharmacol. 716, 78-93. doi: 10.1016/j. ejphar.2013.01.068

Zhang, R.-X., Ren, K., and Dubner, R. (2013). Osteoarthritis pain mechanisms: basic studies in animal models. Osteoarthr. Cartil. 21, 1308-1315. doi: 10.1016/ j.joca.2013.06.013

Zhao, J., Mysona, B. A., Wang, J., Gonsalvez, G. B., Smith, S. B., and Bollinger, K. E. (2017). Sigma 1 receptor regulates ERK activation and promotes survival of optic nerve head astrocytes. PLoS One 12:e0184421. doi: 10.1371/journal.pone. 0184421 
Zhao, M.-G., Ko, S. W., Wu, L.-J., Toyoda, H., Xu, H., Quan, J., et al. (2006). Enhanced presynaptic neurotransmitter release in the anterior cingulate cortex of mice with chronic pain. J. Neurosci. 26, 8923-8930. doi: 10.1523/JNEUROSCI.2103-06. 2006

Zhu, S., Wang, C., Han, Y., Song, C., Hu, X., and Liu, Y. (2015). Sigma-1 receptor antagonist BD1047 reduces mechanical allodynia in a rat model of bone cancer pain through the inhibition of spinal NR1 phosphorylation and microglia activation. Med. Inflamm. 2015, 1-11. doi: 10.1155/2015/26 5056

Zimmermann, M. (1986). Ethical considerations in relation to pain in animal experimentation. Acta Physiol. Scand. Suppl. 554, $221-233$.
Conflict of Interest Statement: The authors declare that the research was conducted in the absence of any commercial or financial relationships that could be construed as a potential conflict of interest.

The handling Editor declared a past co-authorship with several of the authors.

Copyright (c) 2019 Carcolé, Zamanillo, Merlos, Fernández-Pastor, Cabañero and Maldonado. This is an open-access article distributed under the terms of the Creative Commons Attribution License (CC BY). The use, distribution or reproduction in other forums is permitted, provided the original author(s) and the copyright owner(s) are credited and that the original publication in this journal is cited, in accordance with accepted academic practice. No use, distribution or reproduction is permitted which does not comply with these terms. 